ONE HUNDRED AND EIGHTY-SECOND SCIENTIFIC MEETING LECTURE AT THE ROYAL VETERINARY COLLEGE, LONDON

22 JULY 1966

Chairman: Professor F. R. BeLL, Royal Veterinary College, London

\title{
Some nutritional parameters in the ecology of infectious disease
}

\author{
By Howard A. SchneIder, Institute for Biomedical Research, \\ Education and Research Foundation, American Medical Association, \\ Chicago, Illinois
}

Professor Bell, Ladies and Gentlemen:

The great pleasure I had anticipated in responding to the invitation of The British Nutrition Society and the University of London to address this audience has been dimmed by the passing from among us, just days past, of Mr Alfred Bacharach. The American Institute of Nutrition extends its sympathy to its sister society on the loss of one of its distinguished members and as one of the members of the American Institute of Nutrition I would wish to dedicate this address as a memorial to my departed friend. There is considerable relevance in my doing this, for it was Alfred Bacharach, more than 20 years ago, who was the first to discern the hope that lay in the beginnings of the work which I will try to summarize here. I regret, more than I can say, that he is not among us this afternoon.

There is a special appropriateness that I should cross the Atlantic to come to London to lay this work before you, for like all human enterprises this one, too, has a history; and the history of this inquiry into the relationship of nutrition to resistance and susceptibility to infectious disease had its beginning here in London, in the studies of Professor W. W. C. Topley, Director of the London School of Hygiene and Tropical Medicine. These studies, which gave rise to what came to be known as experimental epidemiology, and which are known to you all, had their inception when Professor Topley (I9I9), in his Goulstonian Lecture, declared that the time was then ripe to inquire, by means of laboratory experiment, concerning the general biological basis of epidemic infectious disease. When Professor Topley spoke, the medical world was still reeling from the great influenza pandemic of I9I8I9. And reel it might, for while preening itself in the hubris generated by the golden age of bacteriology, medical knowledge had suffered an humiliating and deflating experience in the eyes of laymen all over the world. The influenza pandemic had come without warning, exacted its terrible toll, and now, just as mysteriously had waned, all the while men of medicine stood bewildered, speaking, if they spoke at all, in a babble of theory and conflicting ideas. Pandemic influenza was a shocking challenge to medicine. As Professor Toynbee warns us, a societal challenge calls forth a response, or paralyses a culture. The challenge of pandemic influenza called forth two responses: one was the investigation of the disease itself, which led to the discovery of the virus, unknown in 1918-19, and to studies on vaccines, etc., all of which goes on right down to the present day; but the second response, in the mind of Professor Topley, was a different one and which started, really, a train of thought 
one result of which has brought me before you this evening. It was Professor Topley's hypothesis that, apart from the special nature of the infectious pathogenic agent itself, there lay discoverable principles at the base of the epidemic phenomenon in general. Some of these might be unknown, as witness the influenza catastrophe and mystery, and Professor Topley suggested that by appropriate population models involving laboratory animal hosts and infectious diseases which were natural to them, valuable information might be obtained and a sound base laid for a biology of epidemic disease. This was the start of the English school of experimental epidemiology.

In America, soon after, in the Rockefeller Institute for Medical Research, an American school of experimental epidemiology was started by the prescience of Dr Simon Flexner, its director, and was elaborated by my late chief, Dr Leslie T. Webster. But all this for a reason different from that in London. In New York several stocks of mice, purchased from dealers, had been commingled into a breeding colony to serve the uses of the Rockefeller investigators. An epizootic of mouse typhoid had broken out and decimated the colony, much to everyone's dismay. Flexner had visited Topley in his laboratory and had seen the beginning experiments with mice and a naturally transmitted disease of mice, what we would now call mouse salmonellosis, and was then called mouse typhoid. The same disease was causing havoc in the New York mouse colonies. Very well--the Americans decided to make a deep study of what, in superficial terms, was but an annoying frustration. But the influence of Topley is clearly evident in the American decision and in the 3 years, I940-3, that I worked with Webster, this influence was frequently acknowledged.

It is an historical irony that both of these leaders, Topley and Webster, died in the same year, I943.

This has been a somewhat lengthy preamble, but $I$ think that it is useful to set these facts forward on this occasion before an audience containing nutritionists, for I hope it will explain how one of their own outlook found himself with a foot in another world of scientific endeavour, and how it might now come about that nutritional explanations can, at long last, be given a hearing by students of infectious disease who have, like any branch of science, important preoccupations of their own.

There is not time now to review the accomplishments, and the differences in outlook, which grew from and between the two schools of experimental epidemiology. Two publications are available (Webster, I932; Greenwood, Hill, Topley \& Wilson, 1936) which will do this. It will serve our purposes here if I say that the work I will now describe and summarize was started with Webster in New York in 1940 , and continued by me, at the Rockefeller, after Webster's death in 1943 until my departure for Chicago in I965. I have had my hand at this for just precisely 25 years and I was encouraged by the generous support of the late Dr Herbert Gasser, Director of the Rockefeller Institute, and by the equally warm support of the late Dr Thomas M. Rivers, Director of the Hospital of the Rockefeller Institute. If these two men despaired of my progress in these investigations, as well they might, they kept their counsel to themselves, and from them, let me here say publicly, I heard nothing but helpful words of encouragement and support. 
And in the laboratory, through the years, I have been fortunate to have had the successive assistance of Drs Norton D. Zinder, Henry N. Wood, Derek Hobson, Robert W. Colburn, Charles H. Hill and Roland Hill.

At this point in my report to you I have two choices: I could continue a chronological history which, with its blind alleys, twists and turns, retracings and defeats would interest me, but I fear would bore you with its tedium. As any researcher knows, this kind of account would be the true course of events and progress, if progress it is. However, I shall elect a second choice, a logical explication of the position we now stand on with the knowledge that in beginning it we may turn time inside out and use early what came late in our understanding. In short, I hope to answer your question, 'Where are we?' by an air-line of logic derived from experiments and leave the bus tour, with stops at ruins and monuments, to some other occasion. As any air traveller knows, it takes a while to get to the airport, but now we are ready to begin.

It is my thesis, drawn from laboratory experiments with mice and their infection with Salmonella typhimurium, that the disease mouse salmonellosis can be favourably influenced and the frequency of survivorship increased to any limit we may set, by the feeding to the mice of minute amounts of a new class of organic substances, the pacifarins, which are present, again in minute amounts, in the natural world of foodstuffs. This new class of substances, the pacifarins, is distinct from all of the presently known items of nutrition, and can be set apart from vitamins and antibiotics.

The key to all this lies in the design of the experiments, the strategy of our approach, and although we have been led to invent some occasional new tactics, it is the strategy that I wish to emphasize here.

The new strategy will be the clearer if we first consider what any student of infectious disease would list as the parameters, a priori, which one would include in a laboratory model of infectious disease which would hopefully reveal the role of nutrition in disease. These I have listed in Table I.

With this list (Table I) before us we made the following choice for our model. We chose mouse stocks free of Salmonellae (Host Factor 7) which at once decided that we would investigate so-called 'natural resistance', i.e., the response of hosts encountering the pathogen for the first time. All experiments were conducted at

Table I. A priori parameters in the infectious disease model (mouse salmonellosis)

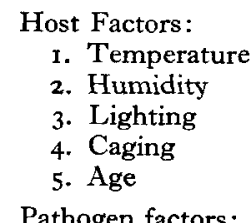

6. Sex

7. Previous exposure to the pathogen

8. Genetic constitution

9. Nutrition

Pathogen factors:

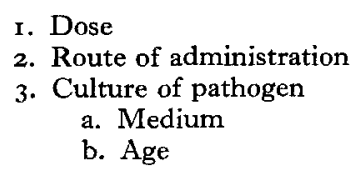


$80^{\circ} \mathrm{F} ; 50 \%$ relative humidity; a I 2 h light day of artificial illumination (fluorescent lights, approximately 25 foot-candles at the cages); the mice were individually caged on mesh floors in the suspended galvanized iron cages; the mice were infected at an age of 6-7 weeks; both sexes were tested, but most of the work was performed with males (Host Factors I-6). The virulent S. typhimurium pathogen populations were cultivated for use in still broth cultures incubated at $37^{\circ} \mathrm{C}$ for $18 \mathrm{~h}$, centrifuged, diluted in sterile pyrogen-free saline and administered by intraperitoneal injection of $0.25 \mathrm{ml}$ volumes containing 1000 viable organisms (Pathogen Factors $\mathrm{I}-3$ ). All survivorship experiments were observed for 30 days post injection and the parameters chosen as above yielded the desired range of results, i.e., some mice died, some mice survived. The frequency of these events was our index of the changes we sought now to bring about by dietary manipulation (Host Factor 9).

\section{The choice of the nutritional parameters}

The mouse populations we have just described were, of course, not living on air but on traditional stock diets. It was, indeed, a fundamental presupposition of ours that if now we changed the dietary regimen of the mice, survivorship frequencies would be changed. But what, precisely, should be elected as the 'changed dietary regimen'? There are, really, an unlimited number of such changes available to us. All legitimate matters for inquiry might be, for example, the infinite permutations and combinations of intakes of individual amino acids, carbohydrate and lipid

\section{Table 2. The experimental diets}

Diet roo - 'Natural diet'

Ground whole wheat

Dried whole milk

$\mathrm{NaCl}$

Diet I9I - 'Synthetic diet'

Casein (Labco, vitamin-free)

Glucose (cerelose)

Salts W-2

L-Cystine

Water-soluble vitamins

Thiamine hydrochloride

Riboflavine

Pyridoxine hydrochloride

Calcium pantothenate

Nicotinic acid

Choline chloride

p-Aminobenzoic acid

Inositol

66

33

$\mathbf{1}$

100

$18 \cdot 0$

$72 \cdot 55$

4.0

0.2

0.25

mg

$2 \cdot 5$

$5 \cdot 0$

$2 \cdot 5$

10.0

25.0

$100 \cdot 0$

$5 \cdot 0$

$100 \cdot 0$

$250 \cdot 0$

Fat-soluble vitamins, in cottonseed oil (Wesson)

$\beta$-carotene

Viosterol (I 70 i.u.)

2-methyl-I, 4-naphthohydroquinone diacetate

$\alpha$-Tocopheryl acetate

Total

Both diets: distilled water $a d$ lib. 
sources, mineral elements and the vitamins. All this we set aside, temporarily. Instead we chose to seek the consequences, for infection, of the comparison of a semi-synthetic diet, containing in synthetic or purified form, the classical and by now traditional amounts of casein, glucose, cottonseed oil, mineral salts and vitamins in a diet adequate for mouse growth and life, beginning as weanling stocks-with a simple but excellent diet of natural foodstuffs, whole wheat, whole dried milk, sodium chloride and drinking water, all ad lib. The composition of these two diets is listed in Table 2.

The choice was dictated by the presupposition that 'natural' diets might contain some special items, not yet known, which would be important for this issue. We were thus gambling that there was more hope in examining qualitatively the world of foodstuffs for something new than in quantitatively tinkering with the list of things we already knew.

\section{The addition of new parameters to the model}

The model infectious disease thus contrived and its initial parameters chosen, we must now come to grips with the necessities which led to the refinement of some of these parameters and the specification of some new ones which proved crucial to this work.

In Table I, Host Factor 8, we listed the genetic constitution of the mice as a host parameter. This needs special explication. Webster's (r937) work had demonstrated that the natural resistance of mice to salmonellosis was under genetic control and in our laboratory we had Webster's inbred homozygous stocks selected for resistance and for susceptibility. We also had a random-bred, non-selected stock. Our dietary manipulations, synthetic $v$. 'natural', resulted in survivorship differences only in the random-bred stock. The inbred stocks were unmoved by this manipulation and, respectively, survived or died independently of the diet. This startled us, but having lived with this fact for some time we have accommodated to it and we now view this as an instance of the separation of genotypes by selection to a point where an environmental manipulation, at least in the magnitude allowed us here in this original manipulation of a natural source, fails to be meaningful as compared with the magnitude of the events arranged by the genetic composition. Or, stated in another way, the statement that there is a genetic difference in the character 'resistance' between these two inbred and selected stocks can be made because the character thus arranged is independent of environmental, including nutritional, vicissitudes. The random-bred population has, on the other hand, not been pulled apart toward the ends of the scale of things to yield two disparate populations and remains more modally central, which position our choice of parameters had tended to identify, and which has clustered into a Gaussian peak enough genotypes of the continuum so that the peak can be toppled one way or the other by the arranged dietary difference. We can therefore refine Host Factor 8 , if we want to more sensitively detect this dietary effect on infection, and specify, 'random-bred, non-selected genotype'. This is a far cry from the usual plea for an inbred genotype as a model component, and it must be confessed, was not what we expected when we began. 
But this talk about host genotype alerted us to the possibility of the role of genotype in the pathogen population. Here again we were rewarded for our efforts for it could be shown (Schneider, I946) that if, dose for dose, we compared the effects of a clonal avirulent salmonella culture with that of a cloned virulent culture, all mice, independent of genotype or diet, survived or died, respectively. Only when we combined the two cultures and used this polymorphic culture as our agent did we obtain survivorship differences. In the inbred stocks of mice, these differences were due to the mouse genotype, with no discernible effects of diet. Only in the random-bred, non-selected stock did we obtain differences in survivorship due to diet. This state of affairs is best set forth in Fig. $I$.

\begin{tabular}{|c|c|c|c|c|}
\hline & \multicolumn{3}{|c|}{ Host-Genotype } \\
\hline & & $\begin{array}{l}\text { Inbred, } \\
\text { selected, } \\
\text { resistant }\end{array}$ & $\begin{array}{c}\text { Random-bred, } \\
\text { (outbred) } \\
\text { ron-selected }\end{array}$ & $\begin{array}{l}\text { Inbred, } \\
\text { selected, } \\
\text { susceptible }\end{array}$ \\
\hline \multirow{3}{*}{ 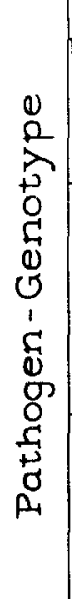 } & $\begin{array}{l}\text { Uniformly } \\
\text { virulent }\end{array}$ & $\begin{array}{l}\text { N-Died } \\
\text { S-Died }\end{array}$ & $\begin{array}{l}\text { N-Died } \\
\text { S-Died }\end{array}$ & $\begin{array}{l}\text { N-Died } \\
\text { S-Died }\end{array}$ \\
\hline & $\begin{array}{c}\text { Mixed } \\
\text { virulent } \\
\text { and } \\
\text { avirulent }\end{array}$ & $\begin{array}{l}\text { N-Survived } \\
\text { S-Survived }\end{array}$ & $\begin{array}{l}\text { N-survived } \\
\text { Dietary effect } \\
\mathbf{S}\end{array}$ & $\begin{array}{l}\text { N-Died } \\
S-D i e d\end{array}$ \\
\hline & $\begin{array}{l}\text { Uniformly } \\
\text { avirulent }\end{array}$ & $\left\{\begin{array}{l}\text { N-Survived } \\
\text { S-Survived }\end{array}\right.$ & $\begin{array}{l}\text { N-Survived } \\
\text { S-Survived }\end{array}$ & $\begin{array}{l}\mathrm{N} \text {-Survived } \\
\text { S-Survived }\end{array}$ \\
\hline
\end{tabular}

Fig. 1. The effect of a natural (N) and a synthetic (S) diet on survivorship following infection in nine different genetic circumstances.

In the synthesis of experience presented in Fig. I we can see that beginning with the simple proposition that it takes a host and pathogen in collision to make for an infectious disease, then, by refining our description of hosts and pathogens in terms of their genetic composition we really have nine models of infectious disease. In only one of these models, the central one, do we have, technically, the best demonstration that diet can indeed influence the outcome. This is our phenomenological position.

Allow me to summarize to this point. On the firm presupposition that nutrition of the host could be shown to affect the outcome of infectious disease we have chosen 
a host, the mouse, and a natural pathogen for mice, $S$. typhimurium, and proceeded to construct a model in which, a priori, we have specified and controlled certain parameters. On this model we have brought to bear a nutritional difference hypothesized as existing between a semi-synthetic diet and a diet of natural foodstuffs. We found it profitable to sophisticate this model further in terms of its genetic dimensions and emerged, thus far, with the recognition that, in genetic terms, the model best suited for our purpose, because it proved to be the most plastic in permitting a dietary difference to exert its effect, was that model in which a randombred, non-selected host was infected with a polymorphic pathogen population containing both avirulent and virulent salmonella genotypes. Our revised model thus has some novel biological features and, I submit, the novel findings to which we will now be led are to be attributed to this attention to model-making rather than to any revolutionary departures in tactical biochemistry and nutrition.

\section{Some tactical artifices}

With the outlines of our strategy now set I wish to set forth very briefly two tactical artifices which (I) improved the resolving power of our model, and thereby reduced our statistical problems, and (2) improved the rate of flow of nutritional information, with obvious benefit. The first artifice is really an exploitation of the operational usefulness of the polymorphic nature of the infecting pathogen population we were led to use. As you will recall, nutritional effects on natural resistance were improved in their detectable magnitude when we infected the mice with a mixture of virulent and avirulent $S$. typhimurium. I should say, parenthetically, that our originally successful use of the traditional single culture with which we began is easily explained on the basis of its probable genetic heterogeneity and polymorphism. On one occasion (Schneider, 1948) we were able to show the spontaneous rise of this heterogeneity with time in a culture originally clonal and subsequently kept on an agar slant in the ice chest for I month. Such heterogeneity and polymorphism is essentially uncontrolled and about all one can say about it is that mutation-selection events in the perpetuated culture inevitably, in time, assure its appearance.

The use of the two distinct cultures of Salmonellae mixed at the time of injection to form the controlled polymorphic (really dimorphic) infecting population, made possible the introduction of an unusual time element. It was found (Schneider, I948) that if short-time intervals, $24-48 \mathrm{~h}$, were allowed to elapse, then the diet difference effect was demonstrably improved. The kinetics of this are illustrated for a typical avirulent-virulent pair relationship in Fig. 2. In long-maintained cultures apparently there occurs a stabilization, by what the microbial geneticist calls 'periodic selection', of characters which affect the kinetics of multiplication of the culture once administered to the host. As this occurs in vitro the consequences in vivo are unpredictable, and will vary from clone to clone during the history of their separate perpetuation and cultivation. Thus, for any given avirulent-virulent pair there will be a unique set of the kinetics of their interaction. Empirically, then, for our purposes we 


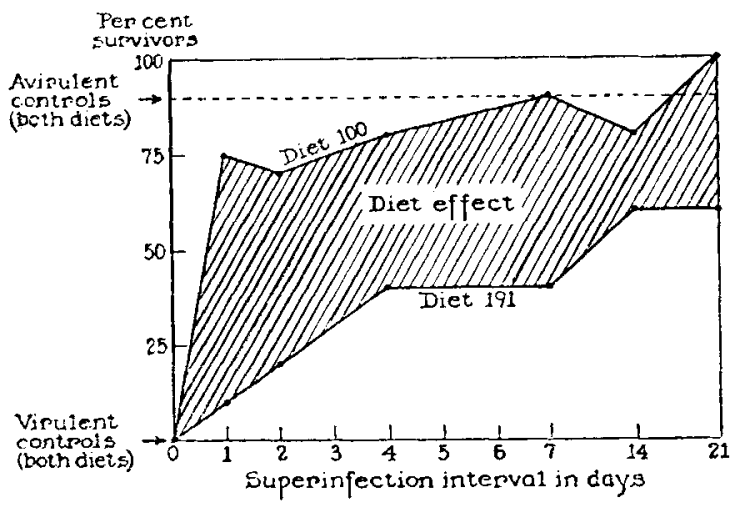

Fig. 2. Difference in survivorship due to diet and as a function of the time interval between the avirulent and virulent challenges.

elect, blindly, stabilized clones from the avirulent and virulent parent cultures, reclone them, and then make an interaction study such as is presented in Fig. 2. For this particular pair we then chose the avirulent-virulent challenge time interval which gave the greatest diet difference effect. In our hands this was usually an interval of 24 or $48 \mathrm{~h}$.

A second artifice was the introduction of a short-time bacteriological datum in our diet effect assay in place of, but firmly correlated with, the previously used 50-60 day survivorship test with its 3 weeks of test diet feeding and the 30 day post infection observation period. The new test (Schneider \& Zinder, 1956) furnished information of equal statistical adequacy, but yielded this information in only ro days after test diets were fed to mice previously prepared on the basal synthetic diet for $3-4$ weeks post weaning. The savings in preparation of materials, test diets, and the sixfold increase in the rate of information flow was the greatest single methodological advance we have made in these studies.

This new artifice, which resulted in the final design of the assay methods used, was based on the introduction of a genetic marker serving to identify the virulent salmonella cells from the arivulent. The marker was a xylose fermentability character. A xylose fermenting mutant was selected out of the original parent virulent population, which latter was xylose fermenting negative as was the avirulent salmonella population. The xylose positive mutant was shown to be (Schneider $\&$ Zinder, 1956) as virulent as the parental stock (one viable cell, intraperitoneally, will kill a mouse of the stock used in the assay). On xylose containing eosin-methylene blue agar plates the xylose positive virulent cells gave rise to opaque black colonies and the xylose negative avirulent cells gave rise to white transluscent colonies. By this means one can enumerate separately the two components of the mixed populations and the dimorphism which was covert (the real basis of the difference in virulence is still unknown) was thereby made overt. All this made possible the analysis of the separate kinetics of increase of the two bacterial strains after they had been admitted to the mouse. The spleen was chosen as the anatomical site of this event and studies (Schneider \& Zinder, 1956) showed that, as predicted, the two separate 
bacterial strains had unique characteristics of multiplication in the mouse which were uninfluenced by our chosen dietary difference. However, when both strains were present in the mouse, the virulent strain was shown on the average to subside into a small, latent population in mice on the wheat diet, which promoted survivorship, and to multiply vigorously until the death of the mice on the semi-synthetic diet. This difference was seized upon as the desired bacteriological datum, visible as early as 2 days post challenge. The details of this have been published (Schneider $\&$ Zinder, 1956), but suffice it here to say that instead of waiting 30 days for mice to die we sacrificed the mice 2 days after challenge, removed and ground up each spleen, spread aliquots of the splenic contents on xylose differential agar plates, incubated overnight and counted opaque black colonies in the resulting mixture of black and white colonies. This count, appropriately interpreted, gave us what philosophers of science call 'the epistemic correlate' of what would have been the result if we had waited for another 27 days and finally counted the total of living and dead mice.

\section{The tracking down of the resistance-promoting factor}

With an assay in hand the rest of the story became a tactical exercise in the fractionation of active foodstuff sources and the determination of properties of the active material, all leading to its isolation. Some clues to chemical structure are in hand, but the final determination of structure is not completed. I will allude to some of these problems, in passing, but in the time that remains allow me to pick up the trail of the isolation of the salmonellosis resistance factor, or SRF as we came to call it.

SRF activity can be found in several cereal grains and in such recondite sources as malted barley sprouts or dried green and black tea. Our fractionation studies bore down largely on the activity in whole wheat (Schneider, 1956). Milling and seiving the wheat showed that activity was in the $25 \%$ of the wheat berry which resists reduction in size, while the $75 \%$ of the berry which comprises the endospermwhite flour fraction lacked activity. Concentration of SRF by milling provided the opportunity to construct diets of high activity and a dose response curve (Fig. 3) revealed the interesting relationship that survivorship frequency, in population probits, was related linearly to the logarithm of the dietary concentration of the SRF source. Other experiments (Schneider \& Zinder, 1956) in which animals were shifted from active diets to inactive basal diets, and vice versa, revealed that SRF was not stored in the mice, and exerted its effects almost immediately on being supplied. A mouse which ate SRF all of its life would, upon withdrawal of SRF, respond in 2 days as if it had never ingested any. This revealed an extremeiy dynamic state of affairs. This has obvious implications for the kinetics of shift of the resistance status of host populations and will, I am certain, be one day a feature of a general theory of epidemic infectious disease.

Returning to the wheat fractionation story, it became all too evident that supplies of whole wheat exhibited considerable variation in SRF activity. In the midst of the struggle to understand the basis of this embarrassing and harassing fact, we stumbled 


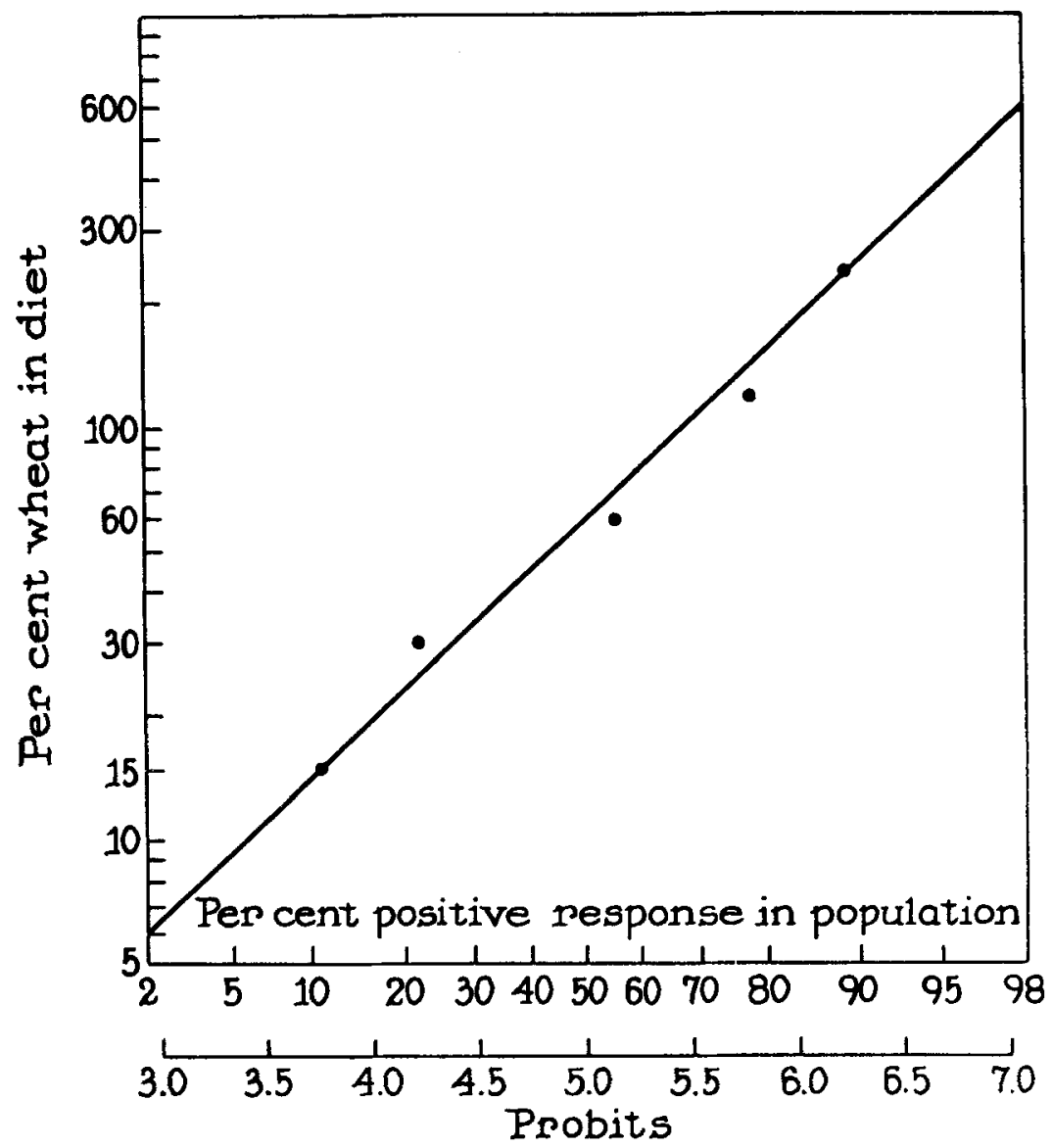

Fig. 3. Response of W-Swiss mouse population to dietary concentrations of the resistance factor.

on to a path which gave our research a whole new direction. As prepared animals were readied for assay we, from time to time, assayed a widening range of foodstuffs for SRF activity, always in the hope that a richer source of activity would fall our way. Commercial dried egg white proved to be a good source of SRF activity. That this was not due to its protein nature was easily shown, for, like the wheat, SRF activity was extracted with methanol, and the extracted residue was inactive.

This was rewarding, but the consequence was more surprising. For commercial dried egg white is a fermented product and experiments quickly showed that sterile, lyophilized fresh egg whites were inactive. But in the laboratory, on the bench, a beaker full of fresh, sterile, inactive egg whites could be fermented by the addition of a pinch of the commercial product from the grocer's shelf, which invariably contained a sizeable dose of a viable, complex microflora, and the lyophilized product of a few days' fermentation at room temperature now had SRF activity. We were next able to show that although many bacterial species present were incapable of generating SRF activity on egg white, this was ultimately shown by a species of Aerobacter present in the complex microfloral population. Further difficulties lay 
ahead, however, for nutrient broth cultures of the Aerobacter proved inactive, in contrast to their success on egg white. Eventually, however, this problem was resolved and a simple synthetic medium of sodium lactate, ammonia and salts, under aeration, allowed the biosynthesis of SRF activity by the Aerobacter. SRF activity is found in the medium and negligible amounts in the cells.

Here, at long last, was the answer to our problem of SRF supply. Before I turn next to some of the chemical features of SRF, allow me to comment on the significance for nutrition of the microbial origins of SRF. For so very long we had thought of SRF as an intrinsic component of the wheat berry much as one thought of, say, its thiamine content. It was with a violent shifting of mental gears that we were forced now to think of SRF as on the berry's husk as a result of microbial action (Aerobacters are invariably found on cereal grains) rather than of it. And yet, the Aerobacter biosynthesis of SRF does not necessarily follow as a consequence of the life of Aerobacter, as witness the failure to biosynthesize SRF in broth culture. SRF can be shown to be biosynthesized when grown on wheat bran, however. So it is true, therefore, that SRF is made by the interaction of Aerobacter and the wheat berry in the field. SRF, it would seem, appears in nature when wheat grows in a natural world wherein, in the natural course of events, Aerobacter ubiquitously and inevitably comes to settle upon it. In the subsequent interaction SRF appears, and its non-appearance would occur only in a field of wheat grown under conditions of the absence of such microbial life, apparently an utterly improbable event. In the ecological reality of the natural world, therefore, wheat berries are bound to have SRF to a varying degree, as cultural conditions vary. When wheat is eaten, therefore, SRF is presented to the ingesting host with consequences for infection as we have seen. We might raise the question whether all this is a subject matter for a science of nutrition. I submit that it is and that a science of nutrition must concern itself with that which is eaten, even though it may not contribute to the substance of muscle, brain or sinew, but ecologically participates in the ingesting host in a decisive way as that host moves about in a world of other and threatening microbial life. When we come to discuss this single instance of a microbial disease from a nutritional viewpoint, to be meaningful we cannot talk only about wheat, we cannot talk only about Aerobacter, but we must talk about the interaction of wheat and Aerobacter. And that, ladies and gentlemen, is why this talk concerns nutrition in a context of ecology and why I believe that nutrition, as a science, has its proper home, not in biochemistry or physiology, which merely provide the tools of analysis, but in ecology, the study of the mutual relations between organisms and their environment.

\section{Some chemical properties of SRF}

The chemical properties of SRF as biosynthesized by our Aerobacter species are indicated in Table 3 . The outstanding chemical property is, of course, the chelating property which extends to all of the elements of the first transitional series. We have been unable, thus far, to incriminate any of these elements in a special role. The iron chelate is active, for example, but so is the des-ferri form.

Our best preparations are fantastically active. An amount of $200-400$ parts per 
Table 3. Properties of the salmonellosis resistance factor (SRF)

r. Destroyed by ashing.

2. Soluble in water, methanol.

3. Insoluble in a wide variety of other organic solvents.

4. Dialyzable.

5. Electrophoretic behaviour: Anion at $\mathrm{pH}>4 \cdot 0$; cation at $\mathrm{pH}<2 \cdot 0$.

6. Heat stability ( $100^{\circ}$ for $30 \mathrm{~min}$ )

a. Stable at $\mathrm{pH} 2$ to 10.

b. Destroyed at $\mathrm{pH}>12 \cdot 0$.

7. Positive Hoepfner and phloroglucinol tests for o-dihydroxyphenols.

8. Sequestering ability for metal ions of the first transitional series. Three active forms of $\mathrm{Fe}^{+++}$chelate recognized: red, violet, blue.

billion in the diet raises survivorship in our model of mouse salmonellosis to $90 \%$ from a base level of $10 \%$.

Elemental analysis reveals carbon, nitrogen, hydrogen, sulphur and oxygen by difference, but no phosphorus. We have resolved out three active forms which vary in their sulphur conteat. But in the absence of good criteria for chemical purity, not much can be inferred from the analytical figures as yet.

\section{The biological categorization of $S R F$}

To be confronted with an organic molecule, biologically active in minute amounts on ingestion, and especially because it is a product of microbial biosynthesis, raises the question whether this new substance is but a special instance of already recognized classes of organic substances. Is it a vitamin, or an antibiotic? The answer is, 'Neither'.

SRF is not required by mice or Salmonellae for their growth or maintenance, and no bacteriostatic or bacteriocidal effects are demonstrable in vitro. In puzzling over this I have come to the view that SRF is properly categorized as a new kind of ecological ectocrine, a category introduced into marine ecology by C. E. Lucas (1947). Dr Lucas has consented to my adoption of his scheme of things under which an ecological ectocrine is defined as a chemical substance, biosynthesized by one species and exerting an effect on the function of another via the external medium. The notion of ecological ectocrines is a very broad one and it is, I think, interesting that vitamins and antibiotics can be subsumed under it: vitamins are biosynthesized by some species and, environmentally delivered, can support the life of other nonsynthesizing but requiring species; and antibiotics are biosynthesized by some microbial species and, environmentally delivered, can inimically affect other microbial species in vitro. But what of SRF, neither a vitamin nor an antibiotic? We have created for it a new class within the idea of ecological ectocrines ('Table 4 ). This

Table 4. Ecological ectocrines (Lucas, 1947)

Class

I. Vitamins

2. Antibiotics

3. Pacifarins
Examples

$A, B_{2}, C, D, E, K$, etc.

Penicillin, streptomycin, terramycin, etc.

Salmonellosis resistance factor (etc.?) 
new class we have dubbed the 'pacifarins', from the Latin 'pacificare', to pacify (Schneider, I963). SRF is thus formally recognized as the salmonellosis pacifarin, the first recognized member of a new class which, I predict, will be found to embrace other, as yet unsought for, pacifarins. Biologically considered, the pacifarins chemically mediate what the ecologist calls 'interspecific non-predator relationships'. There may be subtle intraspecific relationships as well, for we now know that our avirulent Salmonellae biosynthesize the pacifarin and the virulent ones do not. By hindsight we can now see how in the polymorphic salmonella populations, to which our experiments led, there is a 'built-in' supply of the pacifarin. What we have done, apparently, by an additional host-ingested supply, is to bring to bear in an increased concentration a very important item, the pacifarin, that the natural world has, in evolutionary time, spun into the complex ecologic fabric we know as infectious disease. Professor Topley (I9I9) said in his Goulstonian lecture that any real understanding of epidemic disease must include an explanation of how the rise of an epidemic brings with it the seeds of its end. The pacifarins may be that seed.

The subject of nutrition and resistance to infectious disease has never languished for want of talk about it. In the aerial view I have tried to give you this evening of this subject, I hope you will conclude, as I do, that there may be, after all, something very real to talk about indeed.

\section{REFERENCES}

Greenwood, M., Hill, A. B., Topley, W. W. C. \& Wilson, J. (1936). Experimental Epidemiology. London: H.M. Stationery Office.

Lucas, C. E. (1947). Biol. Rev. 22, 270.

Schneider, H. A. (1946). F. exp. Med. 84, 305.

Schneider, H. A. (1948). F. exp. Med. 87, 103.

Schneider, H. A. (1950). In Biological Foundations of Health Education. New York, N.Y.: Columbia University Press.

Schneider, H. A. (1956). Ann. N.Y. Acad. Sci. 66, 337.

Schneider, H. A. (1963). Proc. Am. phil. Soc, 107, 443.

Schneider, H. A. \& Zinder, N. D. (1956). F. exp. Med. ro3, 207.

Topley, W. W. C. (rgrg). Lancet ii, I, 45, 9 I.

Webster, L. T. (1932). Medicine 11, 321 .

Webster, L. T. (1937). F. $\exp$. Med. 65, 26r. 